\section{A general view on multi-step nucleation pathways in sulfate minerals}

\author{
ANDREW LAUER ${ }^{1}$, ALEJANDRO FERNANDEZ- \\ MARTINEZ $^{2}$, ROLAND HELLMANN ${ }^{3}$ AND ALEXANDER \\ E.S. VAN DRIESSCHE ${ }^{2}$
}

${ }^{1} \mathrm{CNRS}$, ISTerre

${ }^{2}$ ISTerre, Univ. Grenoble-Alpes, CNRS

${ }^{3}$ ISTerre

Presenting Author: andrew.lauer@univ-grenoble-alpes.fr

Sulfate minerals are abundant materials both on Earth and Mars [1]. Despite their significant role in both natural and engineered environments, MSO4-H2O systems have received surprisingly little attention in the recent flurry of studies addressing alternative (i.e. non-classical) mechanisms of solution-mediated mineral formation [2]. One exception is $\mathrm{CaSO} 4$, where extensive experimental work has revealed a rather complex mineralization process, involving different stages and precursor species [3,4].

Spurred by these findings, we have now extended our research to other sulfate minerals: celestine ( $\mathrm{SrSO} 4)$ and barite (BaSO4). Potentiometric co-titration experiments have identified different nucleation pathways that, in the case of celestine, include the consumption of bound ions. This is shown through a rigorous quantitative treatment of data from an ion-selective electrode, optrode, and conductivity probe. In addition, a metastable precursor of celestine was found and characterized. High dosing rate titrations can reach a supersaturation regime where this precursor forms, and reveal that the two phases have different nucleation mechanisms.

Illustrated is a typical equimolar co-titration experiment result. From this data, nucleation time can be found for each probe thorough derivative analysis, and speciation can be predicted through comparisons with previously published datasets.

Based on the results from these different (i.e. $\mathrm{Ca}, \mathrm{Sr}, \mathrm{Ba}$ ) sulfate minerals, we are able to identify the key questions that still need to be resolved before a holistic model of the nucleation pathway of solid phases in the MSO4-H2O system is attained.

[1] Alpers et al., (2000) Reviews in Mineralogy and Geochemistry, 40.

[2] Van Driessche et al. (2017) New Perspective on Mineral Nucleation and Growth, Springer-verlag.

[3] Van Driessche et al (2012) Science, 336, 69-72.

[4] Stawski et al (2016) Nat. Commun. 7, 11177.

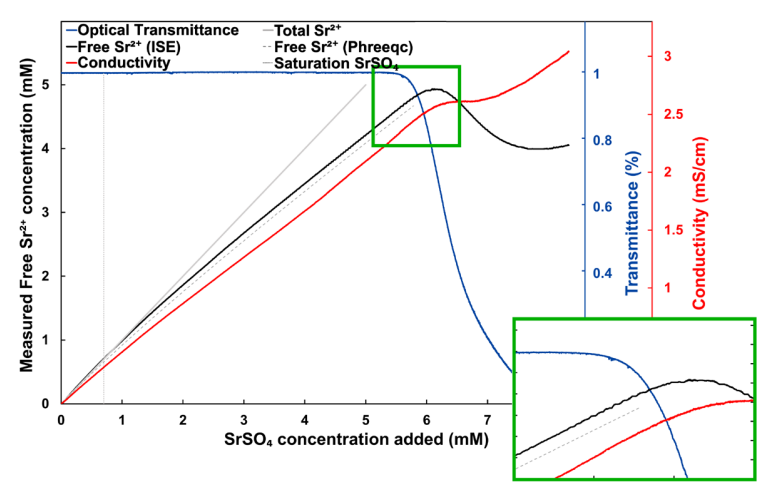

